\title{
A Phase lb trial of CA4P (combretastatin A-4 phosphate), carboplatin, and paclitaxel in patients with advanced cancer
}

\author{
GJ Rustin*, , G Shreeves', PD Nathan', A Gaya', TS Ganesan², D Wang ${ }^{3}$, J Boxall', L Poupard', DJ Chaplin 4 , \\ MRL Stratford ${ }^{5}$, J Balkissoon ${ }^{4}$ and M Zweifel' \\ 'Department of Medical Oncology, Mount Vernon Cancer Centre, Northwood, Middlesex, UK; ${ }^{2}$ The Churchill Hospital, Headington, Oxford, UK; \\ ${ }^{3}$ Josephine Ford Cancer Center/Henry Ford Health System, Detroit, MI, USA; ${ }^{4}$ OXiGENE Inc., San Francisco, CA, USA; ${ }^{5}$ Gray Institute for Radiation \\ Oncology and Biology, University of Oxford, Oxford, UK
}

\begin{abstract}
BACKGROUND: The vascular disrupting agent combretastatin A4 phosphate (CA4P) causes major regression of animal tumours when given as combination therapy.

METHODS: Patients with advanced cancer refractory to standard therapy were treated with CA4P as a 10-min infusion, 20 h before carboplatin, paclitaxel, or paclitaxel, followed by carboplatin.

RESULTS: Combretastatin A4 phosphate was escalated from 36 to $54 \mathrm{mg} \mathrm{m}^{-2}$ with the carboplatin area under the concentration curve (AUC) 4-5, from 27 to $54 \mathrm{mg} \mathrm{m}^{-2}$ with paclitaxel $135-175 \mathrm{mg} \mathrm{m}^{-2}$, and from 54 to $72 \mathrm{mg} \mathrm{m}^{-2}$ with carboplatin AUC 5 and paclitaxel $175 \mathrm{mg} \mathrm{m}^{-2}$. Grade 3 or 4 neutropenia was seen in 17\%, and thrombocytopenia only in $4 \%$ of 46 patients. Grade I-3 hypertension (26\% of patients) and grade I -3 tumour pain ( $65 \%$ of patients) were the most typical non-haematological toxicities. Dose-limiting toxicity of grade 3 hypertension or grade 3 ataxia was seen in two patients at $72 \mathrm{mg} \mathrm{m}^{-2}$. Responses were seen in 10 of 46 (22\%) patients with ovarian, oesophageal, small-cell lung cancer, and melanoma.

CONCLUSION: The combination of CA4P with carboplatin and paclitaxel was well tolerated in the majority of patients with adequate premedication and had antitumour activity in patients who were heavily pretreated.

British Journal of Cancer (2010) I 02, I355-1360. doi:I0.1038/sj.bjc.6605650 www.bjcancer.com

Published online 13 April 2010

(c) 2010 Cancer Research UK
\end{abstract}

Keywords: CA4P; carboplatin; combretastatin A4 phosphate; paclitaxel; phase I trial; vascular disrupting agent

Tumour vascular disrupting agents (VDAs) are a new class of cancer therapies that target the existing vasculature of tumours to cause rapid vascular shutdown in the tumour, leading to cell death (Patterson and Rustin, 2007). Combretastatin A4 Phosphate (CA4P) is a tubulin-binding VDA that displays potent and selective toxicity towards tumour vasculature (Tozer et al, 1999). After single-agent administration in preclinical models, rapid regrowth of the viable tumour rim is observed, which obtains its nutrients from the surrounding normal tissue and blood supply (Salmon and Siemann, 2007). However, when CA4P is combined with a variety of cytotoxic agents, as well as with radiotherapy and antiangiogenesis inhibitors, enhanced tumour control is achieved in vivo (Grosios et al, 2000; Murata et al, 2001; Siemann et al, 2002; Staflin et al, 2006; Yeung et al, 2007).

Four phase 1 trials of CA4P have demonstrated minimal singleagent antitumour activity, and have confirmed that it has vascular disrupting activity according to functional imaging (Dowlati et al, 2002; Stevenson et al, 2003; Rustin et al, 2003a; Cooney et al,

*Correspondence: Dr GJ Rustin; E-mail: grustin@nhs.net

Presented in part at EORTC/NCl/AACR meeting Philadelphia 2005 and International Symposium on Anti-Angiogenic Agents, San Diego 2006. Received 6 January 2010; revised 15 March 2010; accepted 17 March 2010; published online 13 April 2010
2006). Dose-limiting toxicities (DLTs) were seen at doses above $50 \mathrm{mg} \mathrm{m}^{-2}$. In view of the enhanced activity observed when CA4P is combined with cisplatin (El Zayat et al, 1993), carboplatin (Landuyt et al, 2000), CPT11 (Wildiers et al, 2004), or paclitaxel (Yeung et al, 2007) in vivo, human combination studies are the next step.

A phase I trial of carboplatin (dose to produce an area under the concentration curve (AUC) 4 or 5 ), followed $1 \mathrm{~h}$ later by CA4P $27-36 \mathrm{mg} \mathrm{m}^{-2}$, demonstrated grade 3 or 4 thrombocytopenia in 9 of $16(56 \%)$ patients in any course (Bilenker et al, 2005). Decreased renal perfusion was likely the cause of reduced carboplatin clearance and subsequent increase in myelotoxicity (Anderson et al, 2003). This suggests that when administering $\mathrm{CA} 4 \mathrm{P}$ in combination with carboplatin, the reduction in renal perfusion induced by $\mathrm{CA} 4 \mathrm{P}$ needs to have recovered before administering carboplatin. Administering carboplatin/paclitaxel $24 \mathrm{~h}$ after CA4P has been shown to be as effective as administering it before CA4P in MDA MB-231 breast adenocarcinoma xenografts (Edvardsen and Chaplin, personal communication). There is evidence that $24 \mathrm{~h}$ after CA4P administration, there is both continued proliferation of the viable tumour rim and revascularisation, the latter stimulated at least in part by circulating endothelial progenitor cells (Shaked et al, 2006). This might therefore be the best time to administer carboplatin. In clinical practice, carboplatin is frequently given in combination with paclitaxel for 
lung and ovarian cancer. As this combination showed enhanced activity when administered with CA4P in the KAT- 4 model (nude mice bearing human anaplastic thyroid cancer xenografts) (Yeung et al, 2007) and as better therapies are needed for these cancers, a clinical trial was indicated. In view of the toxicity observed by Bilenker et al (2005), we planned a dose-escalation and pharmacokinetic study initially combining CA4P with carboplatin or paclitaxel as doublets before combining all three drugs.

\section{MATERIALS AND METHODS}

\section{Patient selection}

Patients with histologically confirmed cancer, not amenable to standard therapy or refractory to conventional therapy, were eligible for this study. Other eligibility requirements included ECOG performance status $0-2$; life expectancy $\geqslant 4$ months; age $\geqslant 18$ years; adequate bone marrow function (granulocyte count

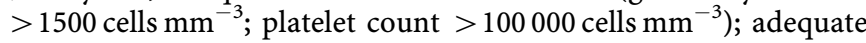
hepatic function (total bilirubin $<1.5 \mathrm{mg}$ per $100 \mathrm{ml}$; ALT and AST $<2.5 \times$ upper limit of normal); adequate renal function with glomerular filtration rate (GFR) measured by EDTA clearance $>50 \mathrm{ml} \mathrm{min}^{-1}$; no other anticancer therapy for 4 weeks; no active concurrent malignancies except cone-biopsied in situ carcinoma of the cervix, or adequately treated basal or squamous carcinoma of skin.

Patients were excluded if they had brain metastases, serious infection or other non-malignant illness, $\geqslant$ grade 2 neuropathy, major surgery within 4 weeks, previously administered radical radiotherapy or evidence of vascular damage from radiotherapy, history of peripheral vascular disease, history of angina, myocardial infarction, arrhythmias, or conditions associated with QTc prolongation, uncontrolled hypertension, or anticoagulation apart from low-dose warfarin for maintenance of central line patency.

\section{Study design}

This was a three-centre, open-label dose-escalation study to initially assess the safety and tolerability of combining CA4P at doses ranging from 36 to $60 \mathrm{mg} \mathrm{m}^{-2}$, with carboplatin doses from AUC 4 to 5, and of combining CA4P at doses from 27 to $54 \mathrm{mg} \mathrm{m}^{-2}$ with paclitaxel doses from 135 to $175 \mathrm{mg} \mathrm{m}^{-2}$. The next stage was combining CA4P with both carboplatin and paclitaxel. The actual dose-escalation scheme achieved is shown in the results section (Table 1). The study was approved by participating hospitals ethical review boards, and all enrolled patients provided written informed consent.

\section{Treatment and dose escalation}

On day 1 of each 21-day cycle, patients received a 10-min infusion of CA4P. Routine premedication was not mandated but if toxicity occurred with the first course, premedication with dexamethasone and metaclopramide was suggested for future courses. On day 2 , $18-22 \mathrm{~h}$ after administering CA4P, patients received a 60 -min infusion of carboplatin or a 3-h infusion of paclitaxel. Glomerular filtration rate was measured by EDTA clearance. The dose of carboplatin corresponded to a target AUC and was calculated using a modified Calvert formula:

Carboplatin $($ dose per cycle in $\mathrm{mg})=($ target $\mathrm{AUC}) \times(\mathrm{GFR}+25)$.

Provided no DLT occurred in any of the three patients per cohort, doses were increased as shown in Table 1. Once it had been ascertained that no DLTs were observed at a CA4P dose of $54 \mathrm{mg} \mathrm{m}^{-2}$ in either of the doublets, patients were then treated with the triplet of drugs at doses shown in Table 1. If a DLT was observed, three additional patients could be recruited to that dose level. The triplet consisted of CA4P on day 1 , followed $18-22 \mathrm{~h}$ later by a 3-h infusion of paclitaxel, then a 60-min infusion of carboplatin. A dose-modification schedule based on grade $\geqslant 2$ neurological or cardiac toxicity and grade 3 or 4 other toxicities was adhered to.

Dose-limiting toxicity was defined as any of the following occurring in the first cycle: QTc prolongation $\geqslant 500 \mathrm{~ms},>$ grade 2 ventricular arrhythmia, grade 3 or 4 non-haematological toxicity (except fatigue/asthenia, nausea and/or vomiting), toxicity resulting in a treatment delay of $>14$ days, absolute granulocyte count $<500$ cells $\mathrm{mm}^{-3}$ for $>5$ consecutive days or febrile neutropenia with granulocyte count $<1000$ cells $\mathrm{mm}^{-3}$, thrombocytopenia $<25000$ cells $\mathrm{mm}^{-3}$ or bleeding episode requiring platelet transfusion, grade $\geqslant 2$ neuropathy, which does not recover to grade 1 within 14 days after scheduled retreatment, or any grade toxicity requiring patient removal from the study on the basis of the judgement of investigators.

The maximum tolerated dose was defined as the maximum dose level of CA4P, administered in combination with carboplatin and paclitaxel, at which one or fewer patients experience a DLT.

\section{Treatment assessment}

Laboratory assessments (including full blood counts) were performed weekly. Tumour evaluations were carried out at screening and then every two cycles. Criteria for response were based on Response Evaluation Criteria in Solid Tumours (RECIST) (Therasse et al, 2000) and response according to CA-125 was based on definitions agreed by the Gynaecologic Cancer Intergroup (Rustin, 2003).

\section{Pharmacokinetics}

The plasma pharmacokinetics (PK) of carboplatin and paclitaxel were evaluated during cycle 1 in all patients receiving study treatment. For carboplatin and paclitaxel PK, blood samples were collected $20 \mathrm{~h}$ after CA4P infusion, on starting the 60-min carboplatin infusion and/or the 3-h paclitaxel infusion, respectively.

Table I Dose-escalation scheme: treatment cohorts with number of patients treated and courses given

\begin{tabular}{|c|c|c|c|c|c|c|c|c|c|c|c|c|c|}
\hline \multirow{2}{*}{$\begin{array}{l}\text { Trial arms } \\
\text { Cohort }\end{array}$} & \multicolumn{5}{|c|}{ Arm I: CA4P/Carboplatin } & \multicolumn{5}{|c|}{ Arm 2: CA4P/Paclitaxel } & \multicolumn{3}{|c|}{ Arm 3: CA4P/Carboplatin/Paclitaxe } \\
\hline & I & 2 & 3 & 4 & 5 & I & 2 & 3 & 4 & 5 & I & 2 & 3 \\
\hline CA4P dose $\left(\mathrm{mg} \mathrm{m}^{-2}\right)$ & 36 & 45 & 45 & 60 & 54 & 27 & 27 & 36 & 45 & 54 & 54 & 63 & 72 \\
\hline Carboplatin AUC & 4 & 4 & 5 & 5 & 5 & - & - & - & - & - & 5 & 5 & 5 \\
\hline Paclitaxel dose $\left(\mathrm{mg} \mathrm{m}^{-2}\right)$ & - & - & - & - & - & 135 & 175 & 175 & 175 & 175 & 175 & 175 & 175 \\
\hline Number of patients & 3 & 3 & 3 & 1 & 5 & 4 & 3 & 3 & 4 & 5 & 4 & 6 & 2 \\
\hline Total number of cycles & 14 & 8 & | | & । & 21 & 16 & || & 10 & || & 20 & 23 & 27 & 6 \\
\hline
\end{tabular}

Abbreviations: $\mathrm{AUC}=$ area under the concentration curve; $\mathrm{CA} 4 \mathrm{P}=$ combretastatin $\mathrm{A} 4$ phosphate. 
Plasma concentration data for paclitaxel and carboplatin plasma ultrafiltrate concentrations were analysed using noncompartmental methods. Peak concentrations $\left(C_{\max }\right)$ were determined manually. The terminal elimination rate constants $\left(\lambda_{z}\right)$ were determined by linear regression analysis of the terminal log-linear part of the concentration-time curve. The total area under the observed plasma concentration-time curve (AUC) was calculated for each analyte from time zero to the last measured concentration, using the linear-log trapezoid rule. Area under the concentration curve values were extrapolated from the last observed time point to infinity by adding the last measured concentration divided by $\lambda_{\mathrm{z}}$.

\section{Statistical analysis}

Non-parametric tests were used to calculate the statistical significance of differences between several groups (the Kruskal-Wallis test), and between two groups for paired (Wilcoxon signed ranksum test) and unpaired (the Mann-Whitney $U$-test) data, and of correlations (Spearman).

\section{RESULTS}

\section{Patients and dose escalation}

Between 27 June 2003 and 1 November 2005, 46 patients with a median age of 58 years were enrolled. Patient characteristics are listed in Table 2.

Table 2 Patient characteristics $(n=46)$

\begin{tabular}{|c|c|}
\hline Characteristics & No. of patients \\
\hline Assessable for response & 46 \\
\hline \multicolumn{2}{|l|}{ Gender } \\
\hline Male & 18 \\
\hline Female & 28 \\
\hline \multicolumn{2}{|l|}{ Age, years } \\
\hline Median & 57 \\
\hline Range & $24-77$ \\
\hline \multicolumn{2}{|l|}{ WHO performance status } \\
\hline 0 & 13 \\
\hline 1 & 29 \\
\hline 2 & 4 \\
\hline \multicolumn{2}{|l|}{ Prior therapy } \\
\hline Chemotherapy & 44 \\
\hline Radiotherapy & 7 \\
\hline Hormonal or biological therapy & 13 \\
\hline \multicolumn{2}{|l|}{ Tumour type } \\
\hline Ovary & 16 \\
\hline Melanoma & 6 \\
\hline Colorectal & 5 \\
\hline Kidney & 5 \\
\hline Lung & 3 \\
\hline Oesophagus & 2 \\
\hline Thyroid & 2 \\
\hline Gastrointestinal stroma tumour & 1 \\
\hline Neuroendocrine tumour & I \\
\hline Cholangiocarcinoma & 1 \\
\hline Leiomyosarcoma of the uterus & 1 \\
\hline Testis & I \\
\hline Primary peritoneal carcinoma & I \\
\hline Fallopian tube & I \\
\hline
\end{tabular}

Abbreviation: $\mathrm{WHO}=$ World Health Organization.
The dose-escalation schedule and the number of patients treated in each cohort are shown in Table 1. A total of 180 cycles were given to 46 patients, with 15 patients completing all 6 cycles. In all, 17 patients withdrew because of tumour progression, three because of early death (all due to tumour progression), five because of toxicity (two patients with grade 3 fatigue, one patient with grade 2 sensory neuropathy, one patient with a grade 4 allergic reaction to carboplatin, and one patient with grade 3 neutropenia and flu-like symptoms), and six for other reasons (one patient needed surgery for small-bowel obstruction, one patient experienced a clonic seizure, one patient was unwilling to continue, two patients had no clear clinical benefit, and the investigator decided to withdraw one patient). Of 180 cycles, 15 (8\%) had to be delayed, mostly because of haematological toxicity.

\section{Haematological toxicity}

The worst grade of haematological toxicity for each patient at each dose level is shown in Table 3. Despite blood counts being performed weekly, grade 3 or 4 thrombocytopenia was only seen in two patients: one in the paclitaxel doublet arm and one in the triplet arm. Grade 3 and 4 neutropenia was only seen in eight patients, all of them in the triplet arm.

\section{Non-haematological toxicity}

Worst drug-related toxicities are summarised in Table 4. Overall, pain was one of the commonest toxicities and almost invariably an exacerbation of preexisting (tumour) pain, typically starting within $1 \mathrm{~h}$ of the commencement of the CA4P infusion and lasting up to a few hours, affecting 30 out of 46 patients (65\%). No patient stopped treatment because of pain, as it was controllable with analgesia that included morphine. Neuropathy (paraesthesia) was more common in the paclitaxel (53\%) and triplet (67\%) arms, but there were still $47 \%$ of patients in the CA4P/carboplatin arm experiencing paraesthesia grade $1-3$.

Rare but important non-haematological toxicities included allergic and neurological reactions. One patient experienced a non-fatal anaphylactic shock (common terminology criteria for adverse events (CTCAE) grade 4) as an allergic reaction to carboplatin. Short-lived and spontaneously resolving muscle weakness of the legs and arms (CTCAE grade 3 and 2) was observed in two patients, although the second patient's symptoms

Table 3 Worst haematological toxicity per patient (all cycles)

\begin{tabular}{|c|c|c|c|}
\hline & \multicolumn{3}{|c|}{ Number of patients } \\
\hline & Carboplatin arm & Paclitaxel arm & Triplet arm \\
\hline \multicolumn{4}{|l|}{ CTCAE grade 1} \\
\hline Anaemia & 7 & 9 & 5 \\
\hline Lymphopenia & 3 & 2 & 2 \\
\hline Neutropenia & 2 & - & - \\
\hline Thrombocytopenia & 4 & 2 & 7 \\
\hline \multicolumn{4}{|l|}{ CTCAE grade 2} \\
\hline Anaemia & 6 & 5 & 6 \\
\hline Lymphopenia & - & - & - \\
\hline Neutropenia & 2 & 6 & 2 \\
\hline Thrombocytopenia & 1 & - & - \\
\hline \multicolumn{4}{|l|}{ CTCAE grade $3-4$} \\
\hline Anaemia & - & 1 & I \\
\hline Lymphopenia & 2 & 3 & I \\
\hline Neutropenia & - & - & 8 \\
\hline Thrombocytopenia & - & 1 & I \\
\hline
\end{tabular}

Abbreviation: $\mathrm{CTCAE}=$ common terminology criteria for adverse events 
Table 4 Worst non-haematological drug-related toxicity per patients (all cycles)

\begin{tabular}{|c|c|c|c|c|c|c|c|c|c|}
\hline \multirow{3}{*}{$\begin{array}{l}\text { Treatment arm } \\
\text { CTCAE grade Toxicity }\end{array}$} & \multicolumn{9}{|c|}{ Number of patients } \\
\hline & \multicolumn{3}{|c|}{$\begin{array}{c}\text { Carboplatin } \\
\text { arm }\end{array}$} & \multicolumn{3}{|c|}{$\begin{array}{c}\text { Paclitaxel } \\
\text { arm }\end{array}$} & \multicolumn{3}{|c|}{$\begin{array}{l}\text { Triplet } \\
\text { arm }\end{array}$} \\
\hline & $\mathbf{I}$ & 2 & 3 & $\mathbf{I}$ & 2 & 3 & I & 2 & 3 \\
\hline Fatigue & 4 & 5 & 3 & 5 & 7 & - & 3 & 5 & - \\
\hline Pain & 6 & 4 & 2 & 2 & 8 & 2 & I & 5 & 0 \\
\hline Sensory neuropathy & 6 & - & I & 8 & I & I & 5 & 3 & - \\
\hline Alopecia & - & - & - & 2 & 12 & - & I & 7 & - \\
\hline Nausea & 4 & 5 & - & 4 & 2 & - & 3 & 4 & - \\
\hline Pain - headache & 1 & 5 & 1 & 3 & I & - & I & 4 & - \\
\hline QTc prolongation & 3 & - & - & 7 & 2 & - & 2 & 1 & - \\
\hline Vomiting & 3 & 2 & 1 & 3 & 3 & - & - & 2 & - \\
\hline Hypertension & 3 & 2 & - & 1 & 2 & - & 3 & - & I \\
\hline Constipation & - & 4 & - & i & 4 & - & - & 2 & - \\
\hline Diarrhoea & 2 & I & & 3 & I & I & - & 2 & 3 \\
\hline Pyrexia & 3 & - & - & 5 & 2 & - & I & - & - \\
\hline Flushing & 3 & I & - & 1 & - & - & 2 & 1 & - \\
\hline Hypotension & - & 1 & - & 1 & 3 & - & I & 2 & - \\
\hline Itching & 3 & - & - & 1 & - & - & 4 & - & - \\
\hline Anorexia & 1 & I & - & - & - & - & 4 & 1 & - \\
\hline Infection & - & 1 & - & - & । & 2 & 2 & 1 & - \\
\hline Myalgia & 1 & - & - & 3 & - & - & 2 & I & - \\
\hline Neurological: muzzy head & 2 & - & - & 2 & - & - & I & - & - \\
\hline Oedema & 2 & 1 & - & 1 & । & - & - & - & - \\
\hline Perianal itching & 3 & - & - & 1 & - & - & I & - & - \\
\hline Rash & - & I & - & 1 & I & 2 & - & - & - \\
\hline Stomatitis & I & - & - & 1 & । & - & 2 & - & - \\
\hline Tachycardia & I & - & - & 2 & - & - & 2 & - & - \\
\hline Agitation & 2 & - & I & 1 & - & - & - & - & - \\
\hline Cough & - & I & - & 1 & - & I & - & - & - \\
\hline Motor neuropathy & - & 1 & I & - & - & 1 & - & - & - \\
\hline Allergy & - & - & $1^{a}$ & - & - & 1 & | & - & - \\
\hline Ataxia & - & - & - & - & - & - & - & 1 & I \\
\hline Dysphasia & - & I & I & - & - & - & - & - & - \\
\hline Dehydration & - & - & - & - & - & I & - & - & - \\
\hline Incontinence & - & - & I & - & - & - & - & - & - \\
\hline Sepsis & - & - & I & - & - & - & - & - & - \\
\hline
\end{tabular}

Abbreviation: $\mathrm{CTCAE}=$ common terminology criteria for adverse events. ${ }^{\mathrm{a}} \mathrm{Grade} 4$ toxicity. may also be explained by malignant meningeal infiltration, which was only diagnosed later.

Ataxia was seen in two patients (CTCAE grade 2 and 3) and resolved spontaneously within a couple of hours. CTCAE grade 3 ataxia occurred 1 day after the first CA4P infusion in one patient and was considered DLT.

Short-lived and spontaneously resolving dysphasia was observed in two patients treated in trial arm 1 at a CA4P dose of $54 \mathrm{mg} \mathrm{m}^{-2}$. One patient was unable to speak for $1 \mathrm{~min}, 2 \mathrm{~h}$ after his second CA4P infusion (initially deemed CTCAE grade 1 by the local investigator, amended to grade 2 upon monitoring as there is no grade 1 for such an event according to CTCAE Version 3.0), and a second patient experienced dysphasia the day after the first infusion of CA4P, lasting less than $5 \mathrm{~min}$. This event was initially deemed grade 2 by the local investigator, but amended to grade 3 later by the principal investigator, and was therefore not captured as a DLT at the time; both patients continued on the trial.

\section{Cardiac toxicity}

In all, 12 of the 46 patients (26\%) experienced hypertension, most were CTCAE grade 1 (Table 4). Dose-limiting toxicity of grade 3 hypertension, which was asymptomatic, was seen in one patient at $72 \mathrm{mg} \mathrm{m}^{-2}$ CA4P. In general, both systolic and diastolic blood pressures were highest at $1 \mathrm{~h}$, followed by slight hypotension $4 \mathrm{~h}$ after CA4P infusion (Figure 1A). Changes in both systolic and diastolic blood pressures correlate significantly with the CA4P dose during the first cycle (Figure $1 \mathrm{~B}$, data shown for systolic blood pressure only). Ten patients were already on antihypertensive medication at study inclusion. Eight of these patients showed at least one episode of hypertension during the study. For comparison, only 4 of the 36 patients not taking antihypertensive medication developed at least one episode of hypertension during the study. Only four patients needed treatment for hypertension related to study medication, of whom two were already on antihypertensive medication. Study guidelines initially advised hydralazine and clonidine to be given when systolic blood pressure exceeded $180 \mathrm{mmHg}$, but this was later amended to glyceryl trinitrate (GTN). Only the last patient in the study experienced hypertension who needed treatment with GTN sublingually (Figure 1C).

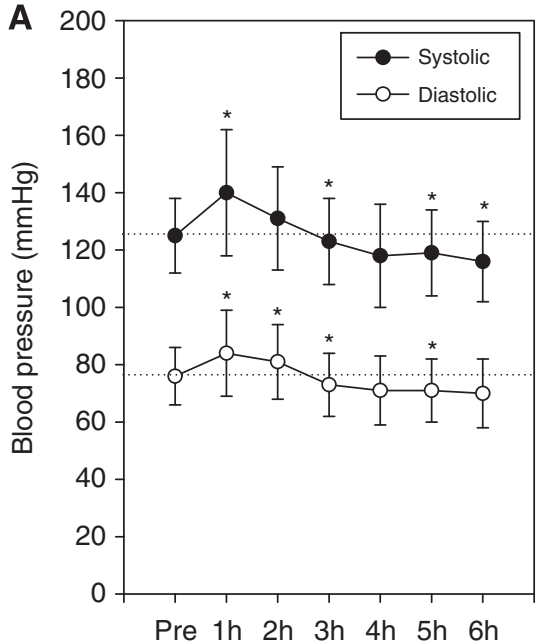

Pre- and hours post-CA4P infusion
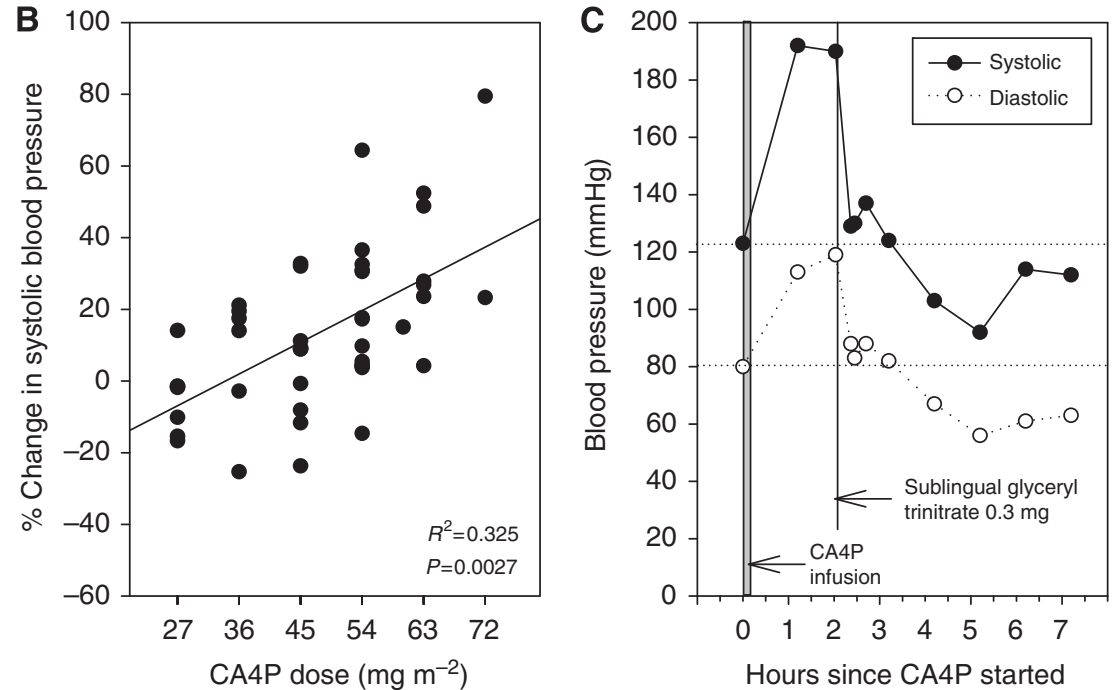

Figure I (A) Systolic and diastolic blood pressure (mean \pm s.d.) before and every hour for $6 \mathrm{~h}$ after combretastatin A4 phosphate (CA4P) infusion in all 46 patients during the first cycle. ${ }^{*} P<0.05$ vs pretreatment measurement. $n=46$ patients. (B) Relationship between CA4P dose (mg $\mathrm{m}^{-2}$ ) and systolic blood pressure changes (in percent) I h after CA4P infusion during the first cycle with fitted regression line. $n=46$ patients. (C) Blood pressure changes in a patient with hypertension after CA4P, responding to $0.3 \mathrm{mg}$ sublingual glyceryl trinitrate. 


\begin{tabular}{|c|c|c|c|c|c|c|c|c|}
\hline $\begin{array}{l}\text { Patient } \\
\text { no. }\end{array}$ & $\begin{array}{c}\text { Carboplatin } \\
\text { AUC } \\
\text { calculated }\end{array}$ & $\begin{array}{c}\text { CA4P } \\
\text { dose } \\
\left(\mathrm{mg} \mathrm{m}^{-2}\right)\end{array}$ & $\begin{array}{c}\text { Paclitaxel } \\
\text { dose } \\
\left(\mathrm{mg} \mathrm{m}^{-2}\right)\end{array}$ & $\begin{array}{l}\text { Carboplatin } \\
\text { AUC measured } \\
\left(\mathrm{mg} \mathrm{min} \mathrm{ml}^{-1}\right)\end{array}$ & $\begin{array}{c}\text { Carboplatin } \\
C_{\max } \\
\left(\mathbf{n g ~ m l} \mathbf{~}^{-1}\right)\end{array}$ & $\begin{array}{c}\text { Haemoglobin } \\
\text { nadir } \\
(\mathrm{g} \text { per } 100 \mathrm{ml})\end{array}$ & $\begin{array}{c}\text { Neutrophil } \\
\text { nadir } \\
\left(\times\left. I 0^{3} \mu\right|^{-1}\right)\end{array}$ & $\begin{array}{c}\text { Platelet } \\
\text { nadir } \\
\left(\times\left|0^{3} \mu\right|^{-1}\right)\end{array}$ \\
\hline 10 & 4 & 45 & - & 4.03 & 24700 & 12.7 & 2.31 & 203 \\
\hline 12 & 4 & 45 & - & 4.08 & 24800 & 8.5 & 5.40 & 302 \\
\hline 13 & 4 & 45 & - & 8.66 & 105000 & 12.0 & 2.26 & 147 \\
\hline 14 & 5 & 45 & - & 5.79 & 41100 & 11.0 & 2.72 & 103 \\
\hline 15 & 5 & 45 & - & 5.55 & 31900 & 8.6 & 3.32 & 175 \\
\hline 17 & 5 & 45 & - & 5.24 & 41300 & 10.0 & 3.31 & 165 \\
\hline 21 & 5 & 54 & - & 6.71 & 31200 & 10.1 & 2.85 & 106 \\
\hline 23 & 5 & 54 & - & 5.38 & 33200 & 10.6 & 2.51 & 215 \\
\hline 32 & 5 & 54 & - & 4.60 & 21000 & 10.1 & 1.78 & 172 \\
\hline 34 & 5 & 54 & - & 3.27 & 11500 & 12.4 & 1.60 & 196 \\
\hline 39 & 5 & 63 & 175 & 3.98 & 15700 & 9.7 & 0.63 & 323 \\
\hline 41 & 5 & 63 & 175 & 3.85 & 21100 & 10.5 & 0.68 & 137 \\
\hline
\end{tabular}

Abbreviations: $\mathrm{AUC}=$ area under the concentration curve; CA4P = combretastatin A4 phosphate.

QTc prolongations $>450 \mathrm{~ms}$ were seen in 15 patients $(33 \%)$ of mostly CTCAE grade 1 , and in three patients with grade 2 , the longest interval being $480 \mathrm{~ms}$. Patients from all three treatment arms were affected. Two of the patients with QTc prolongations were on antihypertensive medication at study entry. Grade 1 tachycardia was seen in $11 \%$ of patients. No cardiac enzyme measurements were taken as none of the patients had clinical symptoms of myocardial ischemia. The only patient with a known history of ischemic heart disease did not experience hypertension or QTc prolongation.

\section{Pharmacokinetics}

Complete plasma data were available for 12 patients for estimation of PK variables for carboplatin (Table 5), and for 31 patients for estimation of PK variables for paclitaxel. Pharmacokinetics could not be estimated for all patients because of sampling problems. The differences between calculated and measured carboplatin AUC did not differ significantly between the different CA4P dose groups, or for the group also receiving paclitaxel, indicating no pharmacological interaction between these drugs using this regimen. Table 5 also shows nadir blood counts demonstrating no relationship with measured carboplatin AUC. A total of 27 patients who received paclitaxel $175 \mathrm{mg} \mathrm{m}^{-2}$ had the AUC of paclitaxel measured, which varied from 463 to $4709 \mathrm{mg} \mathrm{min} \mathrm{ml}^{-1}$, with no significant relationship to the dose of CA4P, indicating no interaction between these drugs using this regimen (data not shown).

\section{Response}

Patients with ovarian cancer Seven of 18 (39\%) patients with epithelial ovarian cancer, primary peritoneal carcinoma, or cancer of the fallopian tube had a response according to RECIST and/or GCIG CA-125 criteria. Of them, one had a confirmed and two had an unconfirmed partial remission (PR) according to RECIST, and a response according to GCIG CA-125 criteria, and four had a response according to GCIG CA-125 criteria only.

Patients with non-ovarian cancer Three of 30 (10\%) patients with non-ovarian cancer showed PR according to RECIST: one in trial arm 2 with extensive small-cell lung cancer, progressing to 2 months after previous response to carboplatin, etoposide, and thalidomide within a phase III trial; another in trial arm 2 with an adenocarcinoma of the oesophagus-gastric junction, for relapse after surgical resection and adjuvant epirubicin/cisplatin/ capectabine, followed by second-line mitomycin C chemotherapy; and a third in trial arm 3 with metastatic melanoma of the skin progressing during first-line trial therapy with dacarbazine and sorafenib.

\section{DISCUSSION}

This phase Ib trial was planned because of the severe myelosuppression observed when combining CA4P with carboplatin in a previous study and the concerns about combining the two different tubulin-binding agents, combretastatin A4 phosphate and paclitaxel. It was the concern about the possibility of CA4P enhancing haematological and neurotoxicity that led us to perform this trial rather than performing a phase II trial with a cohort of patients treated with a lower dose of CA4P, as was the approach followed in the trial of another VDA, DMXAA (Rustin et al, 2003b).

However, this trial has shown that it is safe to combine doses of CA4P that have been shown to reduce tumour blood flow (Anderson et al, 2003; Galbraith et al, 2003; Stevenson et al, 2003) with doses of carboplatin and paclitaxel that are considered standard therapy. In a previous study, CA4P $27-36 \mathrm{mg} \mathrm{m}^{-2}$ was given $1 \mathrm{~h}$ after carboplatin AUC 4 or 5, resulting in $56 \%$ ( 9 of 16) of patients suffering grade 3 or 4 thrombocytopenia (Bilenker et al, 2005). In this study, grade 3 or 4 thrombocytopenia was seen only in $4 \%$ of patients with similar doses of carboplatin but with doses of CA4P up to $72 \mathrm{mg} \mathrm{m}^{-2}$. Administering carboplatin at least $20 \mathrm{~h}$ after CA4P has dramatically reduced myelosuppression. The degree of grade 3 or 4 myelosuppression with the triplet was lower than that observed previously without CA4P (Vasey et al, 2004).

As ataxia and motor neuropathy were DLTs in the first phase I trial of CA4P at $114 \mathrm{mg} \mathrm{m}^{-2}$ (Rustin et al, 2003a), the starting dose when combined with the neurotoxic drug paclitaxel was reduced to $27 \mathrm{mg} \mathrm{m}^{-2}$. In this study, neurotoxicity was seen in the form of sensory neuropathy in $54 \%$ of patients, mostly of CTCAE grade 1 ( $41 \%$ of patients) and probably more related to paclitaxel than to CA4P. Motor neuropathy, ataxia, and dysphasia were observed in a total of six patients $(13 \%)$ at doses between 45 and $72 \mathrm{mg} \mathrm{m}^{-2}$ CA4P and were of short duration, lasting a couple of minutes to a few hours.

Patients who already took medication to control arterial hypertension at the time of study entry were more likely to experience hypertension after CA4P infusion. One patient received GTN for the treatment of CTCAE grade 1 hypertension, which proved to be highly effective in quickly normalising blood pressure, but we now recommend giving GTN as a dermal patch to reduce the side effects of sublingual GTN. The notion that nitrates and calcium channel blockers such as amlodipine are highly effective has 
recently been corroborated by a study in rats (Ke et al, 2009). There remains a concern that hypertension induced by CA4P could cause myocardial or cerebral damage, especially as many elderly patients with cancer have preexisting cardiovascular disease. As we previously demonstrated that CA4P efficiency is dose dependent (Rustin et al, 2003a), and have evidence from this study that hypertension also follows a dose-dependent pattern, we have introduced the prophylactic use of amlodipine in current protocols for the ongoing clinical development of combretastatin A1 phosphate.

Pharmacokinetics showed no evidence of pharmacological interaction between carboplatin or paclitaxel and CA4P. Doselimiting toxicities were CTCAE grade 3 ataxia and CTCAE grade 3 arterial hypertension at $72 \mathrm{mg} \mathrm{m}^{-2} \mathrm{CA} 4 \mathrm{P}$. Thus, the recommended dose for phase II trials is $63 \mathrm{mg} \mathrm{m}^{-2} \mathrm{CA} 4 \mathrm{P}$, combined with carboplatin AUC 5 (based on GFR measured by EDTA clearance), and paclitaxel $175 \mathrm{mg} \mathrm{m}^{-2}$.

\section{REFERENCES}

Anderson HL, Yap JT, Miller MP, Robbins A, Jones T, Price PM (2003) Assessment of pharmacodynamic vascular response in a phase I trial of combretastatin A4 phosphate. J Clin Oncol 21(15): 2823-2830

Bilenker JH, Flaherty KT, Rosen M, Davis L, Gallagher M, Stevenson JP, Sun W, Vaughn D, Giantonio B, Zimmer R, Schnall M, O’Dwyer PJ (2005) Phase I trial of combretastatin A-4 phosphate with carboplatin. Clin Cancer Res 11(4): 1527-1533

Cooney MM, Savvides P, Agarwala S, Wang D, Flick S, Bergant S, Bhakta S, Lavertu P, Ortiz J, Remick S (2006) Phase II study of combretastatin A4 phosphate (CA4P) in patients with advanced anaplastic thyroid carcinoma (ATC). J Clin Oncol, ASCO Annual Meeting Proceedings Part I, (18S): 5580

Dowlati A, Robertson K, Cooney M, Petros WP, Stratford M, Jesberger J, Rafie N, Overmoyer B, Makkar V, Stambler B, Taylor A, Waas J, Lewin JS, McCrae KR, Remick SC (2002) A Phase I pharmacokinetic and translational study of the novel vascular targeting agent combretastatin A-4 phosphate on a single-dose intravenous schedule in patients with advanced cancer. Cancer Res 62(June 15): 3408-3416

El Zayat AA, Degen D, Drabek S, Clark GM, Pettit GR, Von Hoff DD (1993) In vitro evaluation of the antineoplastic activity of combretastatin A-4, a natural product from Combretum caffrum (arid shrub). Anticancer Drugs 4(1): 19-25

Galbraith SM, Maxwell RJ, Lodge MA, Tozer GM, Wilson J, Taylor NJ, Stirling JJ, Sena L, Padhani AR, Rustin GJ (2003) Combretastatin A4 phosphate has tumor antivascular activity in rat and man as demonstrated by dynamic magnetic resonance imaging. J Clin Oncol 21(15): $2831-2842$

Grosios K, Loadman PM, Swaine DJ, Pettit GR, Bibby MC (2000) Combination chemotherapy with combretastatin A-4 phosphate and 5-fluorouracil in an experimental murine colon adenocarcinoma. Anticancer Res 20(1A): 229-233

Ke Q, Bodyak N, Rigor DL, Hurst NW, Chaplin DJ, Kang PM (2009) Pharmacological inhibition of the hypertensive response to combretastatin A-4 phosphate in rats. Vascul Pharmacol 51(5-6): $337-343$

Landuyt W, Verdoes O, Darius DO, Drijkoningen M, Nuyts S, Theys J, Stockx L, Wynendaele W, Fowler JF, Maleux G, Van den Bogaert W, Anne J, van Oosterom A, Lambin P (2000) Vascular targeting of solid tumours: a major 'inverse' volume-response relationship following combretastatin A-4 phosphate treatment of rat rhabdomyosarcomas. Eur J Cancer 36(14): 1833-1843

Murata R, Siemann DW, Overgaard J, Horsman MR (2001) Interaction between combretastatin A-4 disodium phosphate and radiation in murine tumors. Radiother Oncol 60(2): 155-161

Patterson DM, Rustin GJ (2007) Vascular damaging agents. Clin Oncol (R Coll Radiol) 19(6): $443-456$

Rustin GJ (2003) Use of CA-125 to Assess Response to New Agents in Ovarian Cancer Trials. J Clin Oncol 21(10 Suppl): 187-193

Rustin G, Bradley C, Galbraith S, Stratford M, Loadman P, Waller S, Bellenger K, Gumbrell L, Folkes L, Halbert G (2003b) Dimethyl-
It is encouraging that responses were observed in a variety of tumour types, including ovarian cancer ( 7 of 18 patients responding), small-cell lung cancer, adenocarcinoma of the oesophagus-gastric junction, and malignant melanoma (three patients with PR), demonstrating response in a total of $22 \%$ of all patients (including two patients with unconfirmed response). The high response rate in ovarian cancer demonstrates further evidence that this disease is responsive to vascular strategies, and in consequence, a phase II trial in platinum-resistant ovarian cancer has been completed.

\section{ACKNOWLEDGEMENTS}

We thank Sandy Dozier and Shiao-ping Lu for their invaluable help with data analysis. We acknowledge support from OXiGENE Inc., San Francisco, CA, USA. xanthenone-4-acetic acid (DMXAA), a novel antivascular agent: phase I clinical and pharmacokinetic study. BJC 88: 1160-1167

Rustin GJ, Galbraith SM, Anderson H, Stratford M, Folkes LK, Sena L, Gumbrell L, Price PM (2003a) Phase I clinical trial of weekly combretastatin A4 phosphate: clinical and pharmacokinetic results. J Clin Oncol 21(15): 2815-2822

Salmon BA, Siemann DW (2007) Characterizing the tumor response to treatment with combretastatin A4 phosphate. Int J Radiat Oncol Biol Phys 68(1): $211-217$

Shaked Y, Ciarrocchi A, Franco M, Lee CR, Man S, Cheung AM, Hicklin DJ, Chaplin D, Foster FS, Benezra R, Kerbel RS (2006) Therapy-induced acute recruitment of circulating endothelial progenitor cells to tumors. Science 313(5794): 1785-1787

Siemann DW, Mercer E, Lepler S, Rojiani AM (2002) Vascular targeting agents enhance chemotherapeutic agent activities in solid tumor therapy. Int J Cancer 99(1): 1-6

Staflin K, Jarnum S, Hua J, Honeth G, Kannisto P, Lindvall M (2006) Combretastatin A-1 phosphate potentiates the antitumor activity of carboplatin and paclitaxel in a severe combined immunodeficiency disease (SCID) mouse model of human ovarian carcinoma. Int J Gynecol Cancer 16(4): $1557-1564$

Stevenson JP, Rosen M, Sun W, Gallagher M, Haller DG, Vaughn D, Giantonio B, Zimmer R, Petros WP, Stratford M, Chaplin D, Young SL, Schnall M, O’Dwyer PJ (2003) Phase I trial of the antivascular agent combretastatin A4 phosphate on a 5-day schedule to patients with cancer: magnetic resonance imaging evidence for altered tumor blood flow. J Clin Oncol 21(23): 4428-4438

Therasse P, Arbuck SG, Eisenhauer EA, Wanders J, Kaplan RS, Rubinstein L, Verweij J, Van Glabbeke M, van Oosterom AT, Christian MC, Gwyther SG (2000) New guidelines to evaluate the response to treatment in solid tumors. European Organization for Research and Treatment of Cancer, National Cancer Institute of the United States, National Cancer Institute of Canada. J Natl Cancer Inst 92(3): 205-216

Tozer GM, Prise VE, Wilson J, Locke RJ, Vojnovic B, Stratford MR, Dennis MF, Chaplin DJ (1999) Combretastatin A-4 phosphate as a tumor vascular-targeting agent: early effects in tumors and normal tissues. Cancer Res 59(7): 1626-1634

Vasey PA, Jayson GC, Gordon A, Gabra H, Coleman R, Atkinson R, Parkin D, Paul J, Hay A, Kaye SB, Scottish Gynaecological Cancer Trials G (2004) Phase III randomized trial of docetaxel-carboplatin vs paclitaxel-carboplatin as first-line chemotherapy for ovarian carcinoma. J Natl Cancer Inst 96(22): $1682-1691$

Wildiers H, Ahmed B, Guetens G, De Boeck G, de Bruijn EA, Landuyt W, van Oosterom AT (2004) Combretastatin A-4 phosphate enhances CPT-11 activity independently of the administration sequence. Eur $J$ Cancer 40(2): 284-290

Yeung SC, She M, Yang H, Pan J, Sun L, Chaplin D (2007) Combination chemotherapy including combretastatin A4 phosphate and paclitaxel is effective against anaplastic thyroid cancer in a nude mouse xenograft model. J Clin Endocrinol Metab 92(8): 2902-2909 